\title{
VARIABILIDADE GENÉTICA DE ISOLADOS DE Fusarium oxysporum f. sp. cubense OBTIDOS DE BANANAIS DO NORTE DE MINAS GERAIS ${ }^{1}$
}

\author{
TELMA MIRANDA DOS SANTOS ${ }^{2}$, MARCIA REGINA COSTA ${ }^{3}$, ADELICA APARECIDA XAVIER ${ }^{3}$, \\ SILVIA NIETSCHE ${ }^{3}$, THIAGO PRATES FERNANDES ${ }^{4}$, GLEICE VIVIANE NUNES PEREIRA ${ }^{4}$
}

RESUMO- A banana é uma das frutas tropicais mais consumidas no mundo, respondendo por, aproximadamente, 10\% do comércio mundial de frutas. O mal-do-panamá, causado por Fusarium oxysporum f. sp. cubense (E.F. Smith), é uma das principais doenças da bananeira. Os marcadores moleculares RAPD têm sido extremamente úteis para estudos de identificação taxonômica, análise de variabilidade da virulência em fungos fitopatogênicos, caracterização de raças e variabilidade inter e intraespecifica de populações de diferentes regiões. $\mathrm{O}$ objetivo do trabalho foi avaliar a variabilidade genética de 36 culturas monospóricas de isolados de F. oxysporum f. sp. cubense por meio de marcadores moleculares do tipo RAPD. Foram selecionados 13 primers RAPD, e a análise de dados foi realizada utilizando-se do coeficiente de similaridade de Nei e Li. A partir da amplificação dos primers, foram obtidas 178 bandas, sendo que 167 $(93,82 \%)$ apresentaram polimorfismo entre, pelo menos, dois isolados e apenas $11(6,18 \%)$ apresentaram monomorfismo, demonstrando alta variabilidade entre os isolados. As distâncias genéticas variaram de 5,7 a 54,6\%, sendo a distância média de $30,2 \%$, e a distância média relativa, de 55,3\%. De acordo com a análise de agrupamento (UPGMA), não foram observadas correlações entre os isolados estudados. Os resultados sugerem alta variabilidade genética entre os isolados avaliados, não ocorrendo agrupamento de acordo com a origem geográfica de coleta.

Termos para Indexação: mal-do-panamá, marcadores RAPD, Musa spp., bananeira.

\section{GENETIC VARIABILITY OF Fusarium oxysporum f. sp. cubense ISOLATES OBTAINED FROM BANANA ORCHARDS OF THE NORTH OF MINAS GERAIS}

\begin{abstract}
Banana is one of the most consumed tropical fruits in the world, accounting for approximately $10 \%$ of world trade in fruits. Panama disease, caused by Fusarium oxysporum f. sp. cubense is a major disease of banana. RAPD marker have been used for taxonomic studies, analysis of variability of virulence in pathogenic fungi, characterization of races and variability inter and intra-specific populations from different regions. The objective of present study was to evaluate the genetic variability of 36 isolates of $F$. oxysporum f. sp. cubense using RAPD marker. Thirteen RAPD primers were selected and data analysis was performed using the similarity coefficient of Nei and Li. A total of 178 bands were obtained, of which 167 (93.82\%) showed polymorphism at least two isolates and only $11(6.18 \%)$ showed monomorphism, demonstrating the high variability among isolates. The genetic distances ranged from 5.7 to $54.6 \%$, and the average distance of $30.2 \%$. According to cluster analysis (UPGMA) no correlation among isolates were found. The results suggest a high genetic variability among isolates and no correlation between molecular groupings and their geographical origin were observed.
\end{abstract}

Index terms: Panama disease, RAPD marker, Musa spp., banana tree.

\footnotetext{
${ }^{1}$ (Trabalho 144-10). Recebido em: 08-06-2010. Aceito para publicação em: 10-12-2010. Trabalho de Monografia de Conclusão do Curso de Graduação em Agronomia, Cx. Postal 91, UNIMONTES,39440-000 Janaúba-MG. Apoio: Fapemig.

${ }^{2}$ Eng. Agr. Mestranda em Fitotecnia, UFV, Viçosa, MG. E-mail: telma.miranda@yahoo.com.br

${ }^{3}$ Eng. Agr., Dr., Profs., Dep. Ciências Agrárias, UNIMONTES, Cx. Postal 91, CEP 39440-000 Janaúba-MG. E-mail: marcia.costa@unimontes.br, adelica@unimontes.br, silvia.nietsche@unimontes.br

${ }^{4}$ Estudantes do Curso de Agronomia, UNIMONTES, Cx. Postal 91, CEP 39440-000, Janaúba-MG. E-mails: pratesthiago@yahoo. com; gleiceviviane@hotmail.com
} 


\section{INTRODUÇÃO}

No Brasil, a produção de banana dá-se em todos os estados da federação, com uma área colhida de aproximadamente 510 mil hectares e produção aproximada de 7 milhões de toneladas (CODEVASF, 2008). Minas Gerais destaca-se em quinto lugar, com a produção, em 2007, de 537.778 toneladas em uma área colhida de 36.627 mil hectares e rendimento de $14.683 \mathrm{~kg} / \mathrm{ha}$ (IBGE, 2008).

A cultivar Prata-Anã é a mais plantada no norte de Minas Gerais, por apresentar características organolépticas que agradam às exigências do consumidor dos Estados do Rio de Janeiro, Minas Gerais e Brasília (ABANORTE, 2008). Entretanto, esta cultivar é suscetível a várias doenças, entre as quais se destacam o mal-do-panamá e a Sigatoka-amarela.

O mal-do-panamá é causado por um fungo habitante do solo, Fusarium oxysporum f. sp. cubense (E.F. Smith) Snyder \& Hansen. Em regiões onde a doença ocorre, o impacto é extremamente severo, causando o colapso da atividade, com graves reflexos para a economia local. A doença induz morte prematura de plantas adultas, próximo ou durante o florescimento, e as perdas podem atingir $100 \%$ da produção, dependendo da maior ou menor incidência (PEREIRA et al., 2005). No norte de Minas Gerais essa doença tem assumido grande importância econômica, e de acordo com a Seapa (2008), a redução da produção desde 2007 foi provocada por essa doença.

A utilização de cultivares resistentes constitui-se na estratégia mais segura para o controle da doença ou redução dos prejuízos causados por esse patógeno. O programa de melhoramento possui como objetivo o desenvolvimento de cultivares com maior durabilidade da resistência. Sendo assim, o estudo da diversidade genética das populações dos patógenos em escala local, nas regiões produtoras de banana, poderá fornecer informações valiosas para os programas de melhoramento. Além disso, os estudos sobre tais populações do patógeno e análises genéticas da resistência de genótipos de bananeira a $F$. oxysporum f. sp. cubense, também permitirão futuros estudos epidemiológicos que auxiliarão nas estratégias de controle dessa enfermidade.

Atualmente, diversas metodologias são adotadas visando a estudar a variabilidade genética e a identificação de patógenos, sendo que a maior parte é baseada na utilização de marcadores moleculares (GOUVEIA et al., 2005; ZACCARO et al., 2007).
Dentre as técnicas moleculares mais utilizadas, destaca-se o RAPD (Random Amplified Polymorphic DNA) (ABD-ELSALAM, 2003).

A técnica RAPD apresenta as vantagens de: simplicidade, fácil obtenção de dados, custo relativamente reduzido em relação a outras técnicas moleculares e de aplicabilidade imediata a qualquer tipo de organismo, sem a necessidade de conhecimento prévio do seu genoma. Constitui-se, desta forma, em excelente ferramenta para obtenção de dados de polimorfismo para análise da diversidade genética de fungos (FERREIRA; GRATTAPAGLIA, 1998)

Um ponto a ser ressaltado é que a maioria dos estudos sobre a variabilidade de $F$. oxysporum $\mathrm{f}$. sp. cubense foi realizada em outros países, impedindo a aplicação dos resultados nas condições brasileiras (BENTLEY et al., 1995). No Brasil, Silva (2009) caracterizou a diversidade genética de 66 isolados de F. oxysporum f. sp. cubense coletados em regiões produtoras de Santa Catarina por meio de descritores morfológicos e marcadores moleculares (RAPD e SSR), onde foi observada alta variabilidade com estimativas de similaridade que variaram de 35 a $98 \%$. Desta forma, torna-se evidente a necessidade de um melhor conhecimento deste tipo de estudo nas condições brasileiras, sobretudo em regiões produtoras de banana, como no norte de Minas Gerais.

O objetivo do presente estudo foi avaliar a variabilidade genética de isolados monospóricos de F. oxysporum f. sp. cubense, oriundos de diferentes bananais do norte de Minas Gerais, por meio de marcadores moleculares do tipo RAPD

\section{MATERIAL E MÉTODOS}

Foram avaliados 36 isolados de $F$. oxysporum f. sp cubense provenientes da micoteca do Laboratório de Fitopatologia da UNIMONTES, obtidos de pseudocaule e solo de famílias doentes (Tabela 1). A patogenicidade destes isolados foi realizada em mudas micropropagadas da cultivar Maçã com cerca de $20 \mathrm{~cm}$ de altura. As raízes das mudas foram cortadas na sua extremidade e imersas em uma suspensão de $2,5 \times 10^{5}$ conídios/mL por uma hora, e, em seguida, plantadas em solo arenoso tratada com brometo de metila. Após 40 dias da inoculação, cortaram-se o rizoma as mudas para avaliar a presença de pontuações pardo-avermelhadas. Realizaram o isolamento e a confirmação da presença de $F$. oxysporum f. sp. cubense nos tecidos sintomáticos. 
Para a obtenção do DNA do fungo, os isolados monospóricos foram multiplicados em placas de Petri contendo meio SNA ( $1 \mathrm{~g} \mathrm{KH}_{2} \mathrm{PO}_{4}, 1 \mathrm{~g} \mathrm{KNO}_{3}$, $0,5 \mathrm{~g} \mathrm{MgSO}_{4} \cdot 7 \mathrm{H}_{2} \mathrm{O}, 0,5 \mathrm{~g} \mathrm{KCl}, 0,2 \mathrm{~g}$ Glicose, $0,2 \mathrm{~g}$ sacarose, $20 \mathrm{~g}$ Agar, $1 \mathrm{~L} \mathrm{H}_{2} \mathrm{O}$ ), e após sete dias, cinco discos de $5 \mathrm{~mm}$ de diâmetro foram retirados das bordas destas colônias e transferidos para erlemeyer contendo $40 \mathrm{~mL}$ do meio extrato de malte $(20 \mathrm{~g}$ de extrato de malte, $20 \mathrm{~g}$ ágar, $1 \mathrm{~L} \mathrm{H}_{2} \mathrm{O}$ ), e mantidos durante 72 horas em B.O.D a $25^{\circ} \mathrm{C}$ e fotoperíodo de 12 horas. Por meio de filtração em gaze, o micélio foi coletado e iniciada a extração do DNA do fungo de acordo com a metodologia proposta por Roeder e Broda (1987).

Para a análise de RAPD, as reações de amplificação seguiram a metodologia proposta por Williams et al. (1990). Foi utilizado um volume final por reação de $25 \mu \mathrm{L}$ contendo tampão $10 \mathrm{X}$ Tris $/ \mathrm{HCl} 10 \mathrm{mM} / \mathrm{KCl}$ $50 \mathrm{mM}, \mathrm{MgCl}_{2} 2 \mathrm{mM}, 100 \mu \mathrm{M}$ de cada desoxinucleotídeo (dATP, dTTP, dGTP, e dCTP), 2,5 $\mathrm{MM}$ de primer, 1 unidade de Taq DNA Polimerase, 30ng de DNA genômico de cada isolado. As amplificações foram realizadas em termociclador Eppendorf, modelo Biocycler, sob as seguintes condições: um ciclo a $94^{\circ} \mathrm{C} / 3$ minutos; 40 ciclos de $94^{\circ} \mathrm{C} / 15$ segundos, $35^{\circ} \mathrm{C} / 30$ segundos e $72^{\circ} \mathrm{C} / 1$ minuto; ao final desses, um ciclo a $72^{\circ} \mathrm{C}$ por 7 minutos e logo após foi mantido a $4^{\circ} \mathrm{C}$.

Os primers utilizados foram oligonucleotídeos obtidos do KIT OPERON LIFE: OPA10, OPB10, OPC07, OPC14, OPD04, OPD13,OPF10, OPG05, OPG16, OPH11, OPH18, OPI09 e OPI12 (Tabela 2).

Os produtos resultantes das amplificações foram separados por eletroforese em gel de agarose a $1,2 \%$, a $100 \mathrm{~V}$, em tampão TBE $1 \mathrm{X}$, por duas horas e quarenta minutos, e corados em solução de brometo de etídeo a $0,2 \mathrm{mg} / \mathrm{L}$, por 20 minutos. Os fragmentos amplificados foram visualizados sob luz ultravioleta e fotografados em sistema digital UVP Life Science Software.

Uma matriz de dados envolvendo todos os isolados, atribuindo-se valor igual a 1, se banda homóloga estivesse presente, e 0 , caso contrário, foi utilizada para o cálculo da dissimilaridade através do coeficiente de similaridade de Nei e Li, entre pares de genótipos, obtidos pela expressão $\mathrm{D}_{i, i^{i}}=1$ $\mathrm{S}_{i, i^{\prime}}=1-2 \mathrm{a} /(2 \mathrm{a}+\mathrm{b}+\mathrm{c})$, onde $\mathrm{D}_{i, i^{\prime}}$ : Dissimilaridade entre os isolados x e y; $\mathrm{S}_{i i}$ : similaridade entre os isolados x e y; a: valor que quantifica o número de coincidências do tipo $1-1$; b: valor que quantifica o número de coincidências do tipo 1-0; c: valor que quantifica o número de coincidências do tipo 0-1) (CRUZ; CARNEIRO, 2003). Todos os cálculos de dissimilaridades e construção do dendrograma (pelo método de agrupamento UPGMA - Unweighted Pair-Group Method with Arithmetic Averages) foram efetuados com auxílio do programa computacional GENES (CRUZ, 2001).

\section{RESULTADOS E DISCUSSÃO}

Todos os isolados utilizados foram patogênicos para a cultivar Maçã, e após a constatação de sintomas no rizoma, a presença do patógeno foi confirmada pelo reisolamento e avaliação das suas características.

Foram utilizados 13 primers para a análise de polimorfismo dos 36 isolados. A partir da amplificação desses primers, obtiveram-se 178 produtos de amplificação (bandas) (Tabela 2), sendo que 167 $(93,82 \%)$ apresentaram polimorfismo entre, pelo menos, dois isolados e apenas $11(6,18 \%)$ apresentaram monomorfismo, demonstrando alta variabilidade entre os isolados (Figura 1). Esses valores foram similares aos obtidos por Martins (2005) que, ao realizar análise de polimorfismo em DNA de Fusarium spp., utilizando 14 primers RAPD, observou um total de 166 bandas, sendo 6,1\% monomórficas e 93,9\% polimórficas. Nozaki (2003) não obteve nenhuma banda monomórfica e 72 bandas polimórficas ao analisar os produtos de amplificação de 7 primers RAPD em diferentes isolados de Fusarium sp.. Silva (2009), trabalhando com 66 isolados de F. oxysporum f. sp. cubense coletados em regiões produtoras de Santa Catarina, obteve 99 fragmentos gerados por 10 primers RAPD, sendo 81 bandas polimórficas.

A análise do padrão de bandas de cada primer permitiu a construção de uma matriz binária que foi usada para calcular os valores de dissimilaridade (distância genética) pelo coeficiente de Nei e Li. As distâncias genéticas variaram de 5,7 a 54,6\%, sendo a distância média de $30,2 \%$ e a distância média relativa de 55,3\%. A maior distância (54,6\%) ocorreu entre o isolado 90 proveniente do município de Nova Porteirinha e 128 provenientes de Janaúba, e a menor $(5,7 \%)$ entre os isolados 5 e 106 provenientes de Matias Cardoso e Janaúba, respectivamente. Martins (2005), trabalhando com isolados patogênicos e não patogênicos de Fusarium spp., observou níveis de similaridade entre 10,2 e $100 \%$, segundo o coefi- 
ciente de Jaccard. No trabalho de Silva (2009), foi obtido variabilidade considerável com estimativas de similaridade que variaram de 35 a $98 \%$, entre isolados de $F$. oxysporum f. sp. cubense.

De posse das distâncias genéticas, foi realizada uma análise de agrupamento pelo Método da Ligação Média entre Grupo (UPGMA), com a obtenção do dendrograma (Figura 2). A partir da distância média relativa $(55,3 \%)$, determinou-se um ponto de corte, que permitiu a formação de 13 grupos.

Por meio do uso de marcador RAPD, foi possível constatar alta variabilidade genética entre os isolados de tecido e de solos, porém ausência de relação entre a diversidade genética observada com origens geográficas e tipo de material. Os isolados de todos os municípios foram distribuídos em diferentes grupos, mostrando alta variabilidade entre eles, que pode ser atribuído aos processos de disseminação desse patógeno.

Resultados similares foram obtidos por Martins (2005), os quais relataram a grande variabilidade genética entre os isolados de Fusarium spp. obtidos de um mesmo hospedeiro e de hospedeiros diferentes, não sendo possível fazer qualquer associação em relação à especificidade ao hospedeiro, patogênese e de padrão RAPD, haja vista que seus materiais ficaram dispersos no dendrograma. Os 66 isolados de $F$. oxysporum f. sp. cubense coletados de diferentes regiões produtoras de Santa Catarina foram agrupados em cinco grupos distintos, não havendo associação dos agrupamentos com origens geográficas e características morfológicas da colônia, visto que os isolados foram distribuídos indistintamente nos grupos. Gherbawy (1999) utilizou marcadores RAPD para analisar a diversidade genética entre 20 isolados de 14 formae speciales de $F$. oxysporum. Os isolados foram alocados em três grupos, que não apresentaram correlação com a origem geográfica.
$\mathrm{Na}$ Índia, Sivaramakrishnan et al. (2002), ao analisarem a variabilidade de 43 isolados de $F$. oxysporum f. sp. ciceri, coletados de nove estados, por meio de marcadores RAPD, observaram a existência de três diferentes grupos, sendo que dois destes representaram as raças 1 e 2, e o terceiro foi formado pelas raças $3 \mathrm{e}$ 4. Os marcadores moleculares mostraram que as raças 1 e 2 apresentaram grande diversidade quando comparadas com as raças 3 e 4 . Foi detectado, também, um grande nível de variabilidade genética entre e dentro das raças de F. oxysporum f. sp. ciceri. Bentley et al. (1995), utilizando RAPD, concluíram que os isolados de F. oxysporum f. sp. cubense são geralmente VCG específico e sem nenhuma correlação entre a localização e a cultivar de bananeira. Sugeriram ainda que esta variação genética poderia ser devido à adaptação e coevolução do fungo com o hospedeiro e com os fatores ambientais do local. Leong et al. (2009), caracterizando isolados de $F$. oxysporum $\mathrm{f}$. sp. cubense coletados em diferentes cultivares de bananeira da Malásia e Indonésia, utilizando PCR-RFLP de regiões de IST+5.8S e ERIC-PCR, obtiveram similaridade variando de 42,9 a $100 \%$. Os isolados foram intimamente relacionados independentemente da cultivar de bananeira e localização.

Embora o mal-do-Panamá seja uma das principais enfermidades associadas à cultura da bananeira, estudos acerca da variabilidade genética de $F$. oxysporum f. sp. cubense na região do norte de Minas Gerais são inexistentes, sendo este o primeiro relato. 


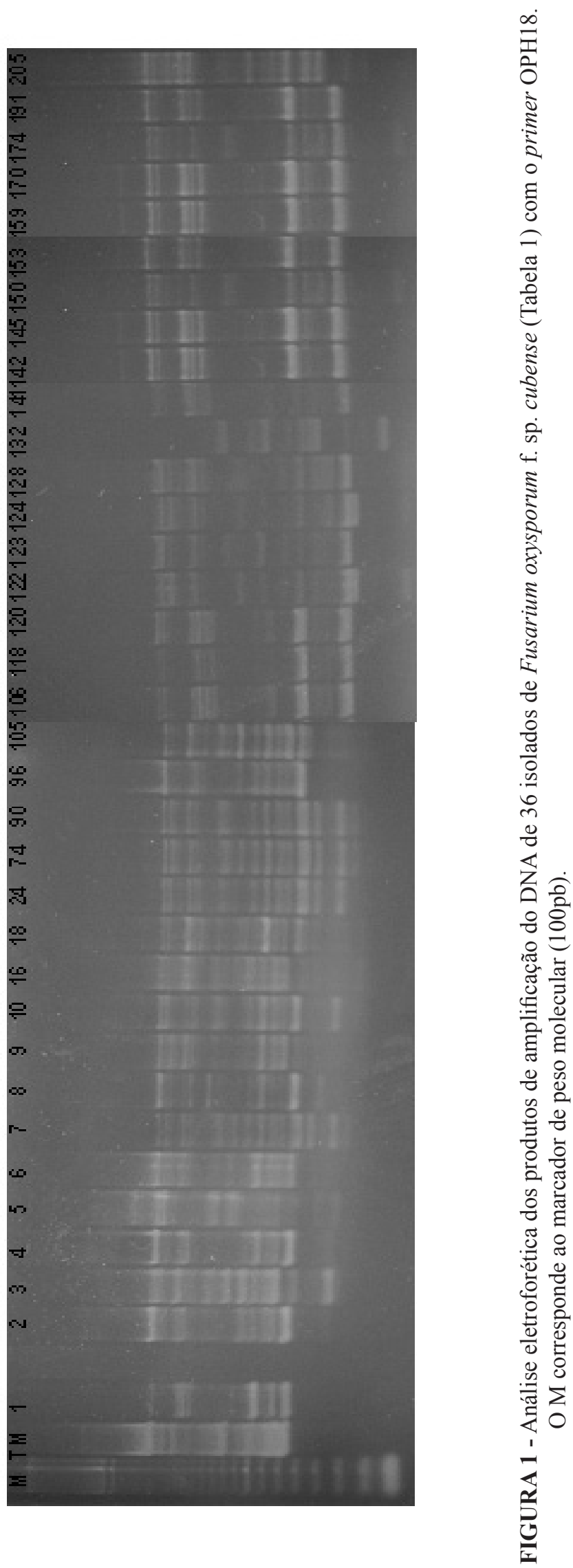




$$
\text { a }
$$


TABELA 1 - Identificação, procedência e origem de 36 isolados de Fusarium oxysporum f. sp. cubense coletados a partir de cultivos com a cultivar Prata-Anã no norte de Minas.

\begin{tabular}{|c|c|c|}
\hline Identificação do Isolado & Procedência & Origem da coleta \\
\hline $\mathrm{TM}$ & Matias Cardoso & Tecido \\
\hline 1 & Matias Cardoso & Tecido \\
\hline 2 & Matias Cardoso & Tecido \\
\hline 3 & Matias Cardoso & Tecido \\
\hline 4 & Matias Cardoso & Tecido \\
\hline 5 & Matias Cardoso & Tecido \\
\hline 6 & Matias Cardoso & Tecido \\
\hline 7 & Matias Cardoso & Tecido \\
\hline 8 & Matias Cardoso & Tecido \\
\hline 9 & Matias Cardoso & Tecido \\
\hline 10 & Matias Cardoso & Tecido \\
\hline 16 & Janaúba & Solo \\
\hline 18 & Janaúba & Solo \\
\hline 24 & Janaúba & Solo \\
\hline 74 & Mocambinho & Solo \\
\hline 90 & Nova Porteirinha & Solo \\
\hline 96 & Nova Porteirinha & Solo \\
\hline 105 & Janaúba & Tecido \\
\hline 106 & Janaúba & Tecido \\
\hline 118 & Jaíba & Tecido \\
\hline 120 & Jaíba & Tecido \\
\hline 122 & Jaíba & Solo \\
\hline 123 & Janaúba & Solo \\
\hline 124 & Jaíba & Tecido \\
\hline 128 & Janaúba & Solo \\
\hline 132 & Janaúba & Tecido \\
\hline 141 & Janaúba & Solo \\
\hline 142 & Janaúba & Solo \\
\hline 145 & Janaúba & Solo \\
\hline 150 & Janaúba & Solo \\
\hline 153 & Janaúba & Tecido \\
\hline 159 & Janaúba & Tecido \\
\hline 170 & Janaúba & Tecido \\
\hline 174 & Janaúba & Solo \\
\hline 191 & Nova Porteirinha & Solo \\
\hline 205 & Nova Porteirinha & Solo \\
\hline
\end{tabular}

Patogenicidade dos isolados foi confirmada em mudas micropropagadas da cultivar Maçã. 
TABELA 2 - Primers utilizados para análise de RAPD, suas sequências e número de bandas monomórficas e polimórficas geradas pela amplificação do DNA dos 36 isolados de Fusarium oxysporum f. sp. cubense.

\begin{tabular}{cccc}
\hline Primer & Sequência 5'-3' & $\mathbf{N}^{\mathbf{0}}$ Bandas monomórficas & $\mathbf{N}^{\mathbf{0}}$ Bandas polimórficas \\
\hline OPA 10 & GTGATCGCAG & 2 & 5 \\
OPB 10 & CTGCTGGGAC & 0 & 12 \\
OPC 07 & GTCCCGACGA & 2 & 10 \\
OPC 14 & TGCGTGCTTG & 1 & 10 \\
OPD 04 & TCTGGTGAGG & 0 & 18 \\
OPD 13 & GGGGTGACGA & 0 & 20 \\
OPF 10 & GGAAGCTTGG & 1 & 8 \\
OPG 05 & CTGAGACGGA & 2 & 6 \\
OPG 16 & AGCGTCCTCC & 2 & 14 \\
OPH 11 & CTTCCGCAGT & 0 & 16 \\
OPH 18 & GAATCGGCCA & 0 & 14 \\
OPI 09 & TGGAGAGCAG & 0 & 15 \\
OPI 12 & AGAGGGCACA & 1 & 19 \\
\hline Total & & $\mathbf{1 1}$ & $\mathbf{1 6 7}$ \\
\hline
\end{tabular}

\section{CONCLUSÃO}

O uso do marcador molecular RAPD permite detectar grande variabilidade genética entre os isolados de F. oxysporum f. sp. cubense coletados no norte de Minas Gerais.

\section{REFERÊNCIAS}

ABANORTE. Associação Central dos Fruticultores do Norte de Minas e Sudoeste da Bahia. Janauba: ABANORTE. Disponível em: $<$ http://www.abanorte. com.br>. Acesso em: 08 mar. 2008.

ABD-ELSALAM, K.A.; ALY, I.N.; ABDEL-SATAR, M.A.; KHALIL, M.S.; VARREET, J.A. PCR identification of Fusarium genus based on nuclearribosomal DNA sequence data. African Journal of Biotechnology, Nairobi, v.2, n. 4, p. 82-85, 2003.

BENTLEY, S.; PEGG, K.G.; DALE, J. L. Genetic variation among Word-wide collection of isolates of Fusarium oxysporum f. sp. cubense analyzed by RAPD-PCR fingerprinting. Mycological Research, Cambridge, v.99, p. 1378-1384, 1995.

CODEVASF. Companhia de Desenvolvimento dos Vales do São Francisco e do Parnaíba/Ministério da Integração Nacional-MI. Cadastro Nacional de Usuários de Recursos Hídricos-CAREH. Relatório por Fase Produtiva Produto data: 17-03-2008. Disponível: $<$ http://www.codevasf.gov.br/>. Acesso em: 20 fev. 2009.
CRUZ, C.D. GENES - versão Windows. Viçosa: Editora UFV, 2001. 642p.

CRUZ, C.D.; CARNEIRO, P.C.S. Modelos biométricos aplicados ao melhoramento genético. Viçosa: Editora UFV, 2003. v.2, 585p.

FERREIRA, M.E.; GRATTAPAGLIA, D. Introdução ao uso de marcadores moleculares em análise genética. 3.ed. Brasília: EMBRAPA-CENARGEM, 1998. p. 220.

GHERBAWY, Y.A.M.H. RAPD analysis of isolates belonging to different formae speciales of Fusarium oxysporum. Cytologia, Tókio, v.64, n.3, p.269-276, 1999.

GOUVEIA, M.M.C.; RIBEIRO, A.; VARZEA, V.M.P.; RODRIGUES JUNIOR, C.J. Genetic diversity in Hemileia vastatrix based on RAPD markers. Mycologia, New York, v.97, n.2, p.396404, 2005.

IBGE. INSTITUTO BRASILEIRO DE GEOGRAFIA E ESTATÍSTICA. Levantamento sistemático da produção agrícola. Disponível $\mathrm{em}:<\mathrm{http}: / / \mathrm{www}$. ibge.gov.br>. Acesso em: mar. 2008.

LEONG, S.K.; BAHARUDDIN, S.; LATIFFAH, Z. Molecular characterization of Fusarium oxysporum f. sp. cubense of banana. American Journal of Applied Sciences, New York, v. 6, n.7, p. 1301-1307, 2009. 
MARTINS, M.K. Variabilidade Genética de Isolados de Fusarium spp. e estudo da interação com a planta hospedeira. 2005. 110 f. Tese (Doutorado em Genética e Melhoramento de Plantas) - Escola Superior de Agronomia Luiz de Queiroz, Universidade de São Paulo, Piracicaba, 2005.

NOZAKI, D. N. Variabilidade genética de $\boldsymbol{F u s a -}$ rium spp. isolados de solos e de bananeiras com sintomas do mal-do-panamá. 2003. 53 f. Dissertação (Mestrado em Proteção de Plantas) - Faculdade de Ciências Agronômicas, Universidade Estadual Paulista Júlio de Mesquita Filho, Botucatu, 2003.

PEREIRA, J.C.R.; PEREIRA, J.R; CASTRO, M.E.A.; GASPAROTTO, L. Ocorrência do mal-dopanamá em bananeira do subgrupo Figo, em Piau, Minas Gerais. Fitopatologia Brasileira, Brasília, v.30, n.5, p.574, 2005.

RAEDER, V.; BRODA, P. Rapid preparation of DNA from filamentous fungi. Letters of Applied Microbiology, Oxford, v. 1, n.1, p. 17-20, 1987.

SEAPA - Secretaria de Estado de Agricultura, Pecuária e Abastecimento. Banana: produção em Minas volta a crescer. 2008. Disponível em: <http://www. agricultura.mg.gov.br/vimpressao.asp?id=941>. Acesso em: 10 dez. 2009.
SILVA, C. M. Análise da diversidade genética por marcadores RAPD e SSR em Fusarium oxysporum f. sp. cubense no Estado de Santa Catarina. 2009. 52 f. Dissertação (Mestrado em Recursos Genéticos Vegetais) - Universidade Federal de Santa Catarina, Florianópolis, 2009.

SIVARAMAKRISHNAN, S.; KANNAN, S.; SINGH, S.D. Genetic variability of Fusarium wilt pathogen isolates of chickpea (Cicer arietinum L.) assessed by molecular markers. Mycopathologia, New York, v.155, n.3, p.171-179, 2002.

WILLIAMS, J.G.; KUBELIK, A.R.; LIVAK, K.J.; RAFALSKI, J.A.; TINGEY, S.V. DNA polymorphism amplified by arbitrary primers are useful as genetic markers. Nucleic Acids Research, London, v. 18, n.1, p. 6531-6535, 1990.

ZACCARO, R. P.; CARARETO-ALVES, L.M.; TRAVENSOLO, R.F.; WICKERT, E.; LEMOS, E.G.M. Utilização de marcador molecular SCAR na identificação de Fusarium subglutinans, agente causal da malformação da mangueira. Revista Brasileira de Fruticultura, Jaboticabal, v.29, n.3, p. 563-570, 2007. 